\title{
An assessment of bioterrorism competencies among health practitioners in Australia
}

\author{
DV Canyon
}

\begin{abstract}
Disaster Health and Crisis Management Unit, Anton Breinl Centre for Public Health and Tropical Medicine, School of Public Health and Tropical Medicine, James Cook University, Townsville, Australia
\end{abstract}

\section{Correspondence}

Dr DV Canyon, Disaster Health and Crisis Management Unit, School of Public Health, Tropical Medicine and Rehabilitation Sciences, James Cook University, Townsville 4811 Australia.

E-mail: deoncanyon@gmail.com

Received 10 October 2008

Revised 21 May 2009

Accepted 12 August 2009
Public health and medical professionals are expected to be well prepared for emergencies, as they assume an integral role in any response. They need to be aware of planning issues, be able to identify their roles in emergency situations, and show functional competence. However, media perceptions and non-empirical publications often lack an evidence base when addressing this topic. This study attempted to assess the competencies of various health professionals by obtaining quantitative data on the state of bioterrorism preparedness and response competencies in Australia using an extensive set of competencies developed by Kristine Gebbie from the Columbia University School of Nursing Center for Health Policy with funding from the US Centres for Disease Control and Prevention. These competencies reflect the knowledge, capabilities, and skills that are necessary for best practice in public health. Sufficient data were collected to enable comparison between public health leaders, communicable disease specialists, clinicians (with and without medical degrees), and environmental health professionals. All health professionals performed well. However, the primary finding of this study was that clinicians consistently self-assessed themselves as lower in competence, and clinicians with medical degrees self-assessed themselves as the lowest in bioterrorism competence. This has important implications for health professional training, national benchmarks, standards, and competencies for the public health workforce.

\section{Introduction}

Public health systems are designed to deal with a regular stream of crises that span a wide range. Health professionals are part of these systems and include, for instance, communicable disease specialists and emergency response personnel, who must be ready to respond to natural and made-made disasters. The public health system has an integral and critical role in responding to threats to public well being, and thus requires a well-prepared workforce. In Australia, a number of anti-terrorism bills were passed in 2002, and the USA passed the Public Health Security and Bioterrorism Response Act in the same year. ${ }^{1}$ This legislation contributed significantly to raising awareness of the need for well-trained health professionals. Subsequently, the Center for Health Policy at Columbia University developed an extensive list of bioterrorism preparedness competencies that were to feature prominently in training courses. ${ }^{2,3}$ In 2003, a report by the Trust for America's Health was published, which prompted more training programs to improve nationwide capacity to respond to natural and unnatural emergency, disaster, and terror events. ${ }^{4}$ Similarly, from 2002 onwards, the Disaster Health and Crisis Management Group at James Cook
University in Australia has developed an integrated and tiered suite of educational programs on disaster health management and bioterrorism in response to demand from over 400 students in Master of Public Health programs. Although some would argue that the spectre of bioterrorism is unlikely, Al-Qa'ida has, almost as a retort, called on its adherents to attempt biological war on US troops in Iraq late in 2006. In an advertisement to attract new recruits, Abu Hamza al-Muhajir, Al-Qa'ida's operational chief in Iraq at the time, reputedly said: 'The field of Jihad can satisfy your scientific ambitions and the large American bases are good places to test your unconventional weapons, whether biological or dirty, as they call them'. ${ }^{5}$

In 2005, the US was awarded a D + (scale: A-F) for preparedness efforts; ${ }^{6}$ however, an appraisal of public health training programs in 2007 made the positive finding that public health now had a seat at the table in most 'places' and 'incident command' has become a well-known term. ${ }^{7}$ No such evaluation has been performed on Australian institutions and no information exists on bioterrorism competencies of Australian health professionals.

To counter media perceptions and publications lacking an evidence base, this study collected data on the self-assessed

This is an Open Access article distributed under the terms of the Creative Commons Attribution licence (http://creativecommons.org/licenses/by/2.5) OPEN - access which permits unrestricted use, distribution, and reproduction in any medium, provided the original work is properly cited. 
competencies of various health professionals to obtain quantitative data on bioterrorism preparedness and response competencies in Australia with the aim of identifying knowledge gaps and differences between health professions.

\section{Methods}

In this study, 10 self-assessment surveys designed to ascertain the state of preparedness of the bioterrorism response community in Australia were made available from a University website. Although the use of a self-report survey is open to criticism, a well-constructed survey can provide accurate and valuable information. ${ }^{8}$ The sampling strategy represents a combination of criterion-based and convenience approaches. ${ }^{9}$ The targeted participants were the bioterrorism response community (Table 1). Questionnaire responses were collected electronically with security preserved through encryption and a secure server line. ${ }^{10}$

In the first nine surveys, preparedness was evaluated using 100 competencies devised by the Center for Health Policy at Columbia University with a grant from the US Centers for Disease Control and Prevention (CDC). ${ }^{2}$ The content of the tenth survey for public health medicine specialists comprised 15 competencies derived from an Australasian Faculty of Public Health Medicine document. ${ }^{11}$ These self-assessment survey tools were designed to help participants

Table 1 Bioterrorism competency surveys and relevant health-related occupations in each survey

\begin{tabular}{|c|c|}
\hline Category & Relevant occupations \\
\hline Public health leaders & $\begin{array}{l}\text { Department Head, Bureau Chief, Division Chief, } \\
\text { Director, and Deputy Director }\end{array}$ \\
\hline Clinical staff & $\begin{array}{l}\text { Nurse, dentist, physician-anyone providing } \\
\text { direct clinical care in a public health setting }\end{array}$ \\
\hline $\begin{array}{l}\text { Public health } \\
\text { communicable disease } \\
\text { staff }\end{array}$ & $\begin{array}{l}\text { Specifically, outbreak investigator and } \\
\text { epidemiologist, but includes those working with } \\
\text { health outcomes, program evaluation, } \\
\text { immunization, disease identification, and } \\
\text { prevention }\end{array}$ \\
\hline $\begin{array}{l}\text { Environmental health } \\
\text { staff }\end{array}$ & $\begin{array}{l}\text { Specialists in research, environmental health, food, } \\
\text { soil and plants, air pollution, hazardous materials, } \\
\text { toxicologist, water/waste water/solid waste } \\
\text { specialist, sanitarian, and entomologist }\end{array}$ \\
\hline $\begin{array}{l}\text { Public health } \\
\text { laboratory staff }\end{array}$ & $\begin{array}{l}\text { Microbiologist, chemist, toxicologist, physicist, } \\
\text { virologist, entomologist, and non-specified } \\
\text { laboratory professionals with a minimum } \\
\text { qualification of a BSc }\end{array}$ \\
\hline Coroner & $\begin{array}{l}\text { Professionals responsible for providing legally } \\
\text { defensible determinations of the cause of death }\end{array}$ \\
\hline $\begin{array}{l}\text { Public health } \\
\text { information staff }\end{array}$ & $\begin{array}{l}\text { Expert in public relations, media relations, } \\
\text { advocacy, health promotion spokesperson }\end{array}$ \\
\hline $\begin{array}{l}\text { Other public health } \\
\text { professional staff }\end{array}$ & $\begin{array}{l}\text { Professional occupations not described above, } \\
\text { such as health educators, legal professionals, } \\
\text { financial officers, and others }\end{array}$ \\
\hline $\begin{array}{l}\text { Technical and other } \\
\text { support staff }\end{array}$ & $\begin{array}{l}\text { Bookkeepers, clerks, court workers, dispatchers, } \\
\text { license distributors, office machine and computer } \\
\text { operators, telephone operators, legal assistants, } \\
\text { etc. }\end{array}$ \\
\hline $\begin{array}{l}\text { Public health medicine } \\
\text { specialists }\end{array}$ & $\begin{array}{l}\text { Workers in health protection, risk management, } \\
\text { and infectious diseases }\end{array}$ \\
\hline
\end{tabular}

to become aware of the readiness competencies; help participants reflect on their abilities; and help guide the development of profession-oriented training materials.

The survey homepage presented information and links, which led initially to an online consent form and then to the anonymous surveys. Demographics collected included country/state of residence, occupation, qualification, and employer. On completion, survey responses were emailed automatically to the investigator. A popup screen was then generated to provide a summary of participant performance in the categories of prevention, preparedness, response, and recovery.

Recruitment took place by emailing postgraduate students, both current and alumni, who were affiliated with the Anton Breinl Centre at James Cook University from the years 2004 to 2006. The advertisement to participate was sent to 445 valid email addresses. A low response rate was expected from this pool, because how many of these were no longer active was unknown. This population was comprised primarily of mid-career doctors (50\%) and other health professionals, including nurses, epidemiologists, environmental health officers, and administrators. Public health leader participation was also sought through direct communication with Chief Health Officers representing the states and territories in Australia. Thus, the results were expected to represent baseline competencies amongst health professionals who had already received public health training. Ethics approval H2328 was granted for this study by the James Cook University.

\section{Results}

A total of 77 valid responses were received with sufficient representation in four surveys to make a statistical assessment (Table 2). The four surveys were public health leader $(n=6)$, communicable disease control (CDC) specialist $(n=6)$, clinician $(n=39)$, and environmental health practitioner $(n=7)$. When overall response data were split into primary foci (preparedness, response, and prevention), several patterns became clear (Figure 1). Statistical comparison of competencies between survey types was not possible, because each survey type included a different set of questions. Public health leaders, CDC specialists, and environmental health practitioners self-assessed fairly similarly in preparedness and response categories, and in the overall category, but CDC specialists indicated having more competence in prevention. It is to be noted that clinicians under assessed their competency in all categories (Table 3).

When these results were further split into eight secondary categories, additional patterns emerged (Table 2). Health leaders consistently appraised themselves as more competent than other groups in the categories of 'preparedness roles', 'response actions', 'response roles', and 'prevention surveillance', but scored lowest in 'preparedness planning'. Examination of top scores indicated that health leaders excelled in 'preparedness planning' and 'response communication'. CDC specialists appraised themselves with the 
Table 2 Comparison of mean \pm s.d. scores in four surveys (Leaders, CDC, clinical and EnvHealth)

\begin{tabular}{|c|c|c|c|c|}
\hline Competency focus & $\begin{array}{l}\text { Survey } \\
\text { type }\end{array}$ & $\begin{array}{l}\text { No. of assessed } \\
\text { competencies }\end{array}$ & Mean $^{\mathrm{a}} \pm$ s.d. & Top-score \\
\hline \multirow{4}{*}{$\begin{array}{l}\text { Preparedness } \\
\text { planning }\end{array}$} & Leaders & 25 & $3.62 \pm 0.58$ & 4.7 \\
\hline & $\mathrm{CDC}$ & 6 & $4.33 \pm 0.58$ & 3.0 \\
\hline & Clinical & 5 & $3.63 \pm 0.83$ & 0.9 \\
\hline & EnvHealth & 6 & $4.17 \pm 0.58$ & 2.0 \\
\hline \multirow[t]{4}{*}{ Preparedness roles } & Leaders & 10 & $3.92 \pm 0.59$ & 2.3 \\
\hline & $C D C$ & 11 & $3.74 \pm 0.77$ & 3.0 \\
\hline & Clinical & 9 & $3.37 \pm 0.74$ & 0.9 \\
\hline & EnvHealth & 10 & $3.86 \pm 0.87$ & 3.1 \\
\hline \multirow{4}{*}{$\begin{array}{l}\text { Preparedness } \\
\text { communication }\end{array}$} & Leaders & 8 & $3.69 \pm 0.45$ & 1.0 \\
\hline & $C D C$ & 3 & $3.61 \pm 0.65$ & 0.7 \\
\hline & Clinical & 2 & $3.31 \pm 0.73$ & 0.3 \\
\hline & EnvHealth & 2 & $4.29 \pm 0.40$ & 1.0 \\
\hline \multirow[t]{4}{*}{ Response actions } & Leaders & 6 & $3.89 \pm 0.54$ & 1.3 \\
\hline & CDC & 6 & $3.61 \pm 0.55$ & 2.0 \\
\hline & Clinical & 10 & $3.33 \pm 0.89$ & 1.2 \\
\hline & EnvHealth & 3 & $3.71 \pm 0.78$ & 0.6 \\
\hline \multirow{4}{*}{ Response roles } & Leaders & 1 & $4.17 \pm 0.00$ & 0.2 \\
\hline & CDC & 1 & $3.83 \pm 0.00$ & 0.2 \\
\hline & Clinical & 1 & $3.05 \pm 0.00$ & 0.1 \\
\hline & EnvHealth & 1 & $3.86 \pm 0.00$ & 0.1 \\
\hline \multirow{4}{*}{$\begin{array}{l}\text { Response } \\
\text { communication }\end{array}$} & Leaders & 12 & $3.95 \pm 0.51$ & 3.2 \\
\hline & CDC & 3 & $3.89 \pm 0.70$ & 1.0 \\
\hline & Clinical & 2 & $3.29 \pm 0.71$ & 0.2 \\
\hline & EnvHealth & 3 & $3.95 \pm 0.74$ & 0.7 \\
\hline \multirow{4}{*}{$\begin{array}{l}\text { Prevention } \\
\text { surveillance }\end{array}$} & Leaders & 4 & $3.71 \pm 0.42$ & 0.7 \\
\hline & $\mathrm{CDC}$ & 8 & $3.63 \pm 0.78$ & 1.7 \\
\hline & Clinical & 1 & $2.36 \pm 0.00$ & 0.1 \\
\hline & EnvHealth & 1 & $3.43 \pm 0.00$ & 0.3 \\
\hline \multirow{4}{*}{$\begin{array}{l}\text { Prevention } \\
\text { diagnostic/lab actions }\end{array}$} & Leaders & 2 & $3.17 \pm 0.47$ & 0.2 \\
\hline & $\mathrm{CDC}$ & 2 & $4.17 \pm 0.24$ & 0.8 \\
\hline & Clinical & 0 & 0 & 0.0 \\
\hline & EnvHealth & 0 & 0 & 0.0 \\
\hline
\end{tabular}

Abbreviation: CDC, communicable disease control.

${ }^{\text {a }}$ Statistical comparison of competencies in between survey types was not possible, because each survey type included a different set of questions. Data in the primary foci (preparedness, prevention, and response) were separated into eight secondary foci (planning, roles, communication, actions, surveillance, and diagnostic/lab actions). Scores were based on a Likert scale in which 1 was 'not competent' and 5 was 'very competent'. 'Top-score' indicates the mean number of times a competence of 5 was indicated per participant. A total of 15 out of the 90 competencies covered in the four surveys were in common to these health professions. A statistical comparison is presented in Table 3.

highest scores in 'preparedness planning' and 'prevention diagnostics/lab action'. Clinicians consistently indicated lower competence when compared with all other health professionals in every category assessed except preparedness planning. Environmental health professionals (EnvHealth) assessed themselves consistently as more competent than other groups in both communication categories. The number of top scores (Likert score 5) are noted in each category to enable comparison of the subsets of professionals who consider themselves highly competent. When top-score frequencies were graded according to their relative position and summed up, the following order was observed: CDC (28), Leaders (22), EnvHealth (18), and Clinicians (11).

There were too few responses in the Leader, CDC, and EnvHealth surveys to permit analysis of demographic variables. However, there were sufficient Clinician data to permit further analysis. Place of Clinician employment (government $n=34$, non-government $n=5$ ) was tested using a $t$-test and was found to be non-significant in each of the competency categories. Differences between state of residence were likewise determined by one-way analysis of variance to be non-significant. Clinicians with medical degrees $(n=24)$ were compared with clinicians with nursing degrees $(n=15)$ using a $t$-test. Those with medical degrees were observed to consistently assess themselves as possessing significantly less bioterrorism competencies than nurses (Figure 2).

\section{Discussion}

To facilitate comparisons between the four survey types, competencies were pooled into the categories of preparedness, response, and prevention. All competencies in the survey were standard job competencies for any bioterrorismrelated occupation. Preparedness and response were separated further into areas of activity, role awareness, and communication, whereas prevention was separated into surveillance and diagnostics.

Overall differences were minimal and surveys ranged from a score of $3.19 \pm 0.65$ to $3.89 \pm 0.56$ out of a 5 -point Likert scale (Table 2). A very good score would have been over 4.0, but scores over 4.0 are rare. ${ }^{12}$ The only scores over 4.0 in the overall categories were for environmental health practitioners in preparedness and health leaders in response. In a study on general public health competencies in the USA, environmental health workers were shown to be no more competent than other health workers. ${ }^{12}$ However, in the USA, nurses can have 'environmental health' roles, hence these data were not necessarily comparable with Australian data. A search of all major publication databases resulted in no articles that surveyed 'environmental health' competencies in Australia. In this study, the exceptional results for environmental health professionals indicate that they should be involved in activities taking place before, during, and after bioterrorism events. It may well be beneficial to overall preparedness and response efforts if working relationships are extended by developing stronger operational and communication ties between health and environmental health responders.

Indicating oneself as a professional in a health leadership position was supported by a higher-than-average perceived level of competencies, but no exceptional competence was evident. However, Health Leaders scored very well in 'top scores' and the data indicates a subset of leaders who selfassessed as exceptionally competent.

Being a clinician with a medical degree, however, was indicative of lower levels of self-reported competence in bioterrorism. There are a number of possible explanations for 


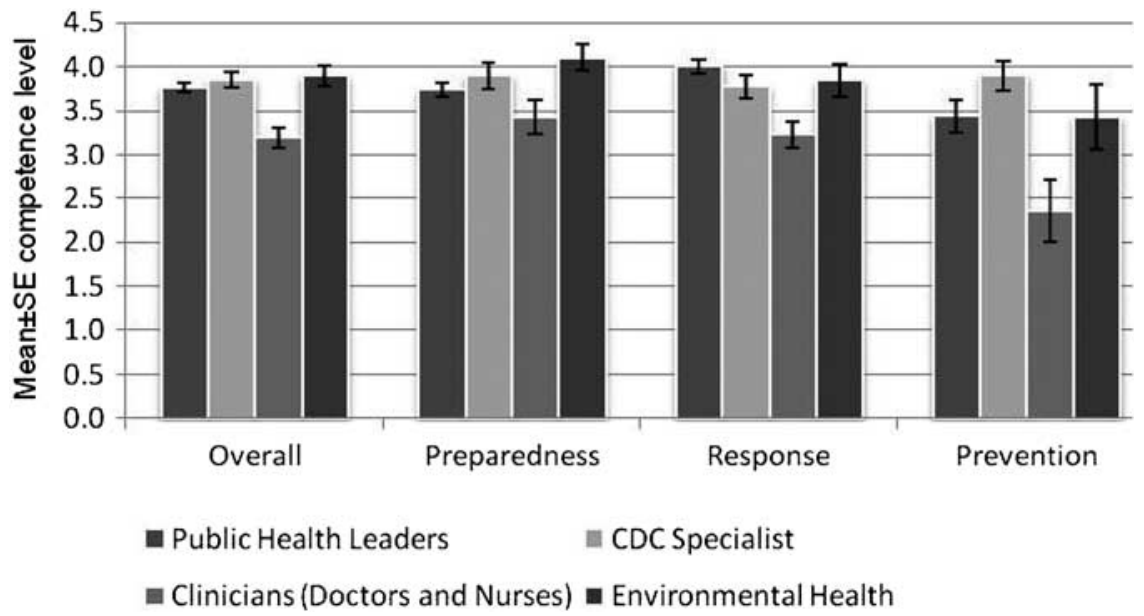

Figure 1 Self-assessed mean bioterrorism competency scores per participant from four different surveys on health professionals presented overall and in three primary foci (preparedness, response, and prevention). Scores were based on a Likert scale in which 1 was not competent and 5 was very competent.

Table 3 Statistical comparison of competencies (mean (s.d.)) that were common to all professions

\begin{tabular}{|c|c|c|c|c|c|}
\hline Competency & Leader $(n=6)$ & $C D C(\mathrm{n}=6)$ & $\begin{array}{l}\text { Clinician } \\
(\mathrm{n}=39)\end{array}$ & $\begin{array}{l}\text { EnvHealth } \\
(\mathrm{n}=7)\end{array}$ & P-value \\
\hline 01 Identifying the agency emergency response plan & $4.00(0.63) \mathrm{a}$ & $4.33(0.82) \mathrm{a}$ & $3.59(1.16) \mathrm{a}$ & $4.71(0.49) \mathrm{a}$ & 0.043 \\
\hline $\begin{array}{l}03 \text { Demonstrating the correct use of all emergency communication } \\
\text { equipment }\end{array}$ & $3.83(0.75) a$ & $3.00(1.10) a$ & $3.21(1.26) \mathrm{a}$ & $4.00(1.16) a$ & 0.259 \\
\hline 04 Demonstrating my functional role(s) in emergency response drills & $4.17(0.41) a b$ & $3.83(0.98) a b$ & $3.28(1.17) \mathrm{a}$ & $4.57(0.54) b$ & 0.014 \\
\hline 05 Implementing my individual bioterrorism response functional role & $4.17(0.41) \mathrm{a}$ & $3.83(0.98) \mathrm{a}$ & 3.05 (1.17)a & $3.86(0.69) a$ & 0.031 \\
\hline $\begin{array}{l}06 \text { Maintaining regular communication with partners in other agencies } \\
\text { involved in emergency response }\end{array}$ & $3.60(0.55) a b$ & 3.80 (1.79)ab & $2.92(1.11) \mathrm{a}$ & $4.29(0.49) \mathrm{b}$ & 0.015 \\
\hline 08 Conducting workforce bioterrorism preparedness programs & $3.83(0.75) a$ & $3.83(1.17) a$ & $3.46(1.02) \mathrm{a}$ & 4.14 (1.07)a & 0.357 \\
\hline $\begin{array}{l}16 \text { Using established communication systems for coordination among } \\
\text { response community during a bioterrorism event, including those for } \\
\text { privileged information }\end{array}$ & $4.00(0.63) a$ & $4.33(0.52) a$ & $3.67(0.96) a$ & $4.29(0.49) a$ & 0.140 \\
\hline $\begin{array}{l}26 \text { Describing the public health role in emergency response in a wide range of } \\
\text { emergencies that might arise }\end{array}$ & $4.17(0.75) \mathrm{a}$ & $3.83(1.47) a$ & $3.77(0.81) a$ & $3.29(1.11) a$ & 0.392 \\
\hline 27 Describing your functional role(s) in emergency response & $4.33(0.52) \mathrm{b}$ & 4.00 (1.27)ab & $3.08(0.98) \mathrm{a}$ & $3.43(0.98) a b$ & 0.013 \\
\hline 28 Identifying your functional role in the agency's bioterrorism response plan & $4.00(0.63) a b$ & $4.17(0.41) \mathrm{b}$ & $3.13(0.92) a$ & $3.86(0.90) \mathrm{ab}$ & 0.007 \\
\hline 29 Describing the chain of command in emergency response & $3.83(0.75) a b$ & $3.67(0.82) \mathrm{a}$ & $3.28(1.05) \mathrm{a}$ & $4.71(0.49) \mathrm{b}$ & 0.006 \\
\hline $\begin{array}{l}30 \text { Describing communication role(s) in emergency response within the } \\
\text { agency using established communications systems, with the media, general } \\
\text { public, and family, neighbors }\end{array}$ & $4.20(0.45) a b$ & $3.67(1.03) a b$ & $3.41(0.91) a$ & $4.57(0.54) \mathrm{b}$ & 0.008 \\
\hline $\begin{array}{l}31 \text { Recognizing unusual events that might indicate an emergency and } \\
\text { describing appropriate action }\end{array}$ & $4.17(0.41) \mathrm{a}$ & $4.33(0.82) a$ & $3.56(1.05) a$ & $4.14(0.69) a$ & 0.121 \\
\hline $\begin{array}{l}32 \text { Applying creative problem solving and flexible thinking to unusual } \\
\text { challenges within your functional responsibilities and evaluating effectives of } \\
\text { all actions taken }\end{array}$ & $4.17(0.75) a$ & $3.83(1.60) \mathrm{a}$ & $3.46(1.07) a$ & $4.43(0.53) a$ & 0.103 \\
\hline $\begin{array}{l}33 \text { Identifying limits to your own knowledge and identifying key system } \\
\text { resources for referring matters that exceed those limits }\end{array}$ & $4.17(0.75) a$ & 4.17 (0.98)a & $3.46(0.94) a$ & $4.29(0.49) a$ & 0.037 \\
\hline
\end{tabular}

All $P$-values refer to (overall) simple factor analysis of variance results; significant overall $P$-values $(P<0.05)$ are shown in italics. Post-hoc Duncan tests (adjusting for multiple pair-wise comparisons by holding an overall significance level of 0.05 ) were carried out to assess significant differences between any two groups; if measurements were found to be significantly different between two groups (as indicated by alphabets a and b), those values are also shown in italics.

this. Although it may reflect a lack of awareness or overconfidence in other groups, or indeed, more honesty in the medical group, it is more likely to reflect a heavier load of competing work priorities and greater demand by this group for more information and training. This result was not surprising given the results in one study, which found that only $20 \%$ of physicians or nurses had previous training in bioterrorism preparedness, but $<15 \%$ felt able to respond effectively to a bioterrorism event. ${ }^{13}$ However, this did not affect their enthusiasm, as over 70\% expressed willingness to 


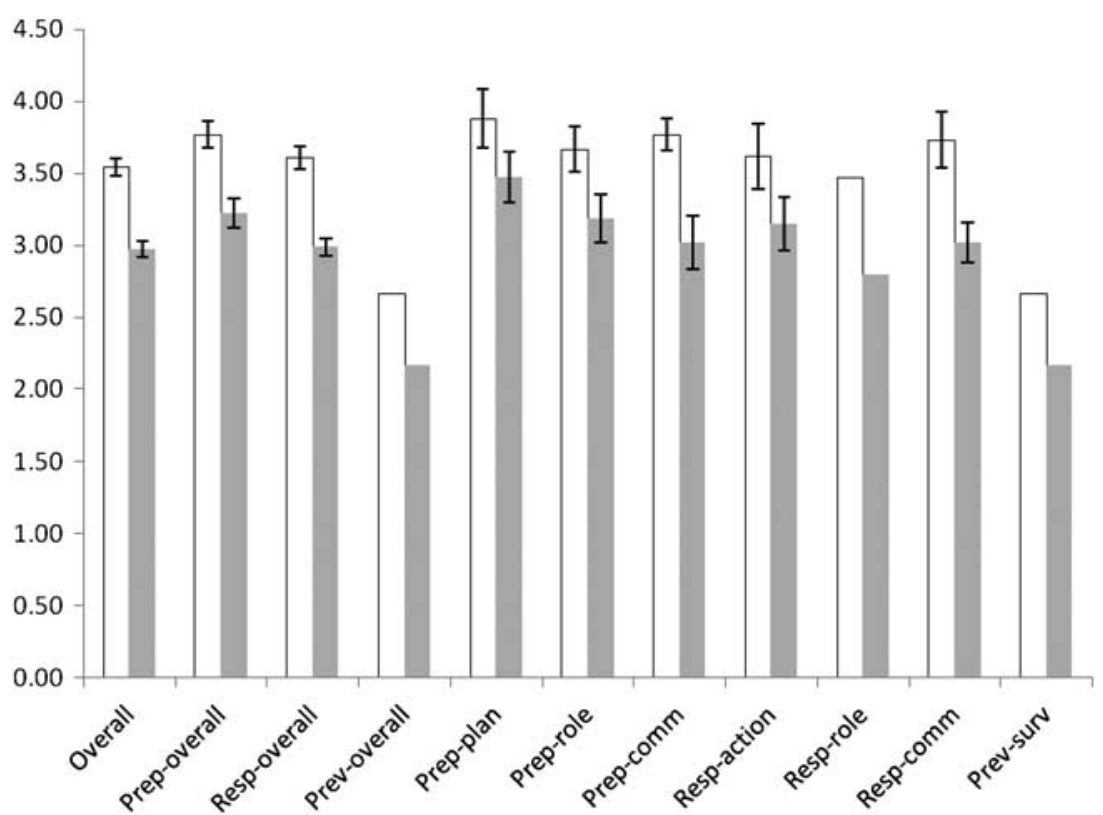

Figure 2 Self-assessed clinician competencies in all the pooled categories separated by those with medical degrees (shaded) and those with nursing degrees (not shaded).

assist the state in the event of a bioterrorist attack. Likewise, a survey of emergency and primary care physicians found that 43 and $21 \%$, respectively, indicated being well prepared to have a role in the event of a bioterrorism attack. ${ }^{14}$ These low figures were confirmed in a survey on physicians in a major metropolitan area, which found that $91 \%$ self-assessed their level of bioterrorism knowledge as being 'fair-poor', $80 \%$ wanted more information, and $83 \%$ wanted training opportunities. $^{15}$ Reporting bias based on profession is unlikely, as contradictory results were obtained in a similar survey in which physicians rated themselves higher than nurses. ${ }^{13}$ When general competencies of public health nurses in the USA were assessed, it was found that they did not feel more than minimally competent with scores averaging 2.5 out of $5{ }^{16}$ Our finding that Australian nurses scored much higher in a specialist area, such as bioterrorism, is indicative of good national standards. However, an average of 3.5 out of 5 still leaves room for improvement. This level of clinical competence was corroborated by a low frequency of 'top scores' in all categories.

Communicable disease control professionals were expected to do well in this survey because of their regular preparedness, response, and prevention activities, as part of outbreak management. However, they were overshadowed by health leaders and environmental health practitioners. CDC scores ranked third in both 'preparedness role' and 'response role' categories, but more 'top scores' were observed in 'response actions'. In Australia, the CDC system is efficiently organized with ongoing monitoring, systematic responses along agreed lines, well-defined roles, and very good service delivery (Professor $\mathrm{R}$ Speare, personal communication).
Australia has not yet adopted a common set of public health, let alone bioterrorism, competencies, and there has been considerable resistance from most educational institutions. In 2009, a fairly generic set of competencies was tabled by the National Public Health Education and Research Program and tentatively accepted by participating public health institutions. Current efforts by Australian health departments to deliver disaster response training to a large proportion of medical and nursing staff is a significant move in the right direction and should raise the level of competencies. In other areas, competency improvements have been associated with comprehensive training events in key content knowledge tests and self-rated competencies. ${ }^{17}$ Emergency preparedness training has also been shown to increase responder confidence in duty performance by two to three times. ${ }^{5}$ The self-assessed results from this study suggest that Australian public health leaders have the necessary competencies to ensure the success of this effort; however, external validation of leaders and their teams may be required to confirm this.

\section{Acknowledgements}

I thank Arjen Boin, Peter Aitken, and Rick Speare for their comments on this paper.

\section{References}

1 US Government. Public Health Security and Bioterrorism Response Act. H.R. 3448, 2002.

2 CHPCU. Bioterrorism \& Emergency Readiness: Competencies For All Public Health Workers. Center for Health Policy, Columbia University: New York City, USA, 2002. 
3 Horney JA, Sollecito W, Alexander LK. Competency-based preparedness training for public health practitioners. J Public Health Manag Pract 2005; 11: S147-9.

4 Markenson D, Reilly MJ, DiMaggio C. Public health department training of emergency medical technicians for bioterrorism and public health emergencies: results of a national assessment. J Public Health Manag Pract 2005;11:S68-74.

5 AFP AP. Al-Qa'ida calls for biological war. The World. The Weekend Australian 2006, 30 September 1-October 13.

6 Trust for America's Health. Ready or not: Protecting The Public's Health From Disease, Disasters And Bioterrorism 2005. Trust for America's Health: Washington DC, USA, 2005.

7 Fraser MR. After 5 years of public health preparedness, are we ready yet? J Public Health Manag Pract 2007;13:3-6.

8 Chatman S. The University of California undergraduate experiences survey: General education objectives, http://www.physics.ucdavis. edu/kiskis/ug_council/sari.pdf (Retrieved 27 October 2005).

9 Patton MQ. Qualitative Research \& Evaluation Methods, 3rd edn, Sage: Thousand Oaks, CA, USA, 2002.

10 James Cook University. IT Support Documentation, Link To Sun One Web Server Documentation 2006, http://docs.jcu.edu.au/ (retrieved on 4 Oct 2008).
11 AFPHM. Competencies For Public Health Medicine Training And Practice In New Zealand (Draft). The Australasian Faculty of Public Health Medicine: Brisbane, Australia, 2006.

12 Bartee RT, Winnail SD, Olsen SE, Diaz C, Blevens JA. Assessing competencies of the public health workforce in a frontier state. J Commun Health 2003;28:459-69.

13 Katz AR, Nekorchuk DM, Holck PS, Hendrickson LA, Imrie AA, Effler PV. Hawaii physician and nurse bioterrorism preparedness survey. Prehosp Disaster Med 2006;21: 404-13.

14 Alexander GC, Larkin GL, Wynia MK. Physicians' preparedness for bioterrorism and other public health priorities. Acad Emerg Med 2006;13:1238-41.

15 Spranger C, Villeqas D, Kazda M, Harris A, Mathew S, Miqala W. Assessment of physician preparedness and response capacity to bioterrorism or other public health emergency events in a major metropolitan area. Disaster Manag Response 2007;5:82-6.

16 Issel LM, Baldwin KA, Lyons RL, Madamala K. Self-reported competency of public health nurses and faculty in Illinois. Public Health Nurs 2006;23:168-77.

17 Reischl TM, Buss AN. Responsive evaluation of competency-based public health preparedness training programs. J Public Health Manag Pract 2005;11:S100-5. 